\title{
A Discussion on the Construction of Talent Team in University Library
}

\author{
LI Jing-Jing ${ }^{1, \mathrm{a}^{*}}$,Wang Qing-Kuan ${ }^{1, \mathrm{~b}}$ \\ ${ }^{1}$ Air and Missile Defense College of Air Force Engineering University \\ $a^{*}$ Corresponding author. Email: bigboy11272000@126.com \\ ${ }^{b}$ Corresponding author. Email: $343133284 @ q q . c o m$
}

\begin{abstract}
Meeting the needs of users is the foundation of library construction. With the development of computer technology and the popularization of network, the user community of the library and the needs of the users all have new features. These changes have led to continuous innovation in the management and service models of libraries. The traditional personnel structure and service model cannot adapt to the needs of the future development of the library. Guided by users' information needs, this paper points out that the network has the realistic significance, construction status and construction of the talent construction of university libraries in the era.
\end{abstract}

Keywords: network era, information users, information needs, subject librarians

\section{INTRODUCTION}

The demand of users directly reflects the demand of society for library, which is the fundamental driving force for the continuous progress and development of libraries. All activities of the library are developed around users. To survive and develop, the library must meet various demands of users [1]. With the rapid development of the network era, people have more access to information in more convenient ways, and their demand for information has changed, which undoubtedly brings great impact to the development of libraries [2]. Faced with challenges, whether libraries can grasp the new features of users' information demand in the network era and do everything possible to meet the changes of users' demands will directly affect the survival and development of libraries.

\section{NEW FEATURES OF UNIVERSITY LIBRARY USERS AND THEIR INFORMATION NEEDS IN THE NETWORK ERA}

\subsection{New Development of Information Users in Universities in the Network Era}

\subsubsection{Expansion of User Groups}

The user groups of traditional university libraries are relatively single and fixed, mainly the teachers, students and scientific researchers who come to the library to borrow documents. Their demand for information is small and narrow [3]. With the rapid development of social information, computer technology and network technology are widely used in libraries, thus connecting all libraries and breaking through the strict boundaries between libraries. University libraries aim to build a system of information resources co-construction and sharing. All users who join the system can use the resources of any library in the system through the coconstruction and sharing network platform. The library is no longer only for teachers and students of the university. In a sense, all network users are actual users of any library. Moreover, with the comprehensive penetration of information, people's information awareness is increasing. Nowadays, university libraries no longer only provide services for teachers and students, but almost cover all departments and fields of the whole university. Every member of the system becomes the service object of the library.

\subsubsection{Changes of User Roles}

The popularization of computers has promoted the development of the network, the transmission of information is increasingly networked, and the acquisition and utilization of information is more convenient, which has changed the role of users. They are not only information users, but also involved in the whole process of information resources integration and sharing. 
They obtain relevant information through a variety of channels and have a dual identity of information request and provision.

\subsubsection{Change of Users' Reading Habits}

With the introduction of the concept of digital library, the electronic information resources and resource databases in library have developed rapidly. While increasing paper collection resources, university libraries also make great efforts to develop electronic information resources. In addition that electronic resources are more convenient and efficient than paper resources, they can be used at the same time. Therefore, more and more users are inclined to read electronic collections.

\subsection{New Features of University Users' Information Demand in the Network Era}

With the rapid development of science and technology, emerging disciplines, interdisciplinary and marginal disciplines are constantly emerging, and the rapid development of modern information technology has brought about a big explosion of network information, the demand of university library users also presents some new features in the face of the chaotic information resources [3].

\subsubsection{Coexistence of Diversity and Personalization}

The diversity of users' demand for information resources is shown as follows:

(1) Diversity of information needs. With the penetration of the concepts of information and intelligence, people's awareness of information is increasing, and their thirst for knowledge is becoming stronger and stronger. The knowledge people need is no longer limited to books, nor to a single specialized knowledge. Ubiquitous information environment and user's own information consciousness make user's information demand diversified.

(2) Diversity of information demand types. The library of the 21 st century is a compound library where digital library and printed library coexist. In the $21 \mathrm{st}$ century, library users can not only enjoy the feeling and cultural connotation of reading traditional paper documents such as books, periodicals and newspapers, but also swim in the ocean of convenient and fast multimedia electronic information resources.

(3) Diversity of information demand models. The popularization of computer technology and network technology enables users to obtain the required information easily and quickly without leaving home. The traditional service retrieval method in the past cannot meet the needs of users. The inherent traditional service mode is perfected while increasing the systematicness. Diversified service mode has become an important subject of current libraries.

The individualization of users' demand for information resources has changed as follows:

Individual differences of users lead to the personalization of information demand. The users of university libraries are mainly composed of researchers, teachers and students of various departments. Due to their different responsibilities in teaching and research activities, they differ in their status, knowledge level, profession, and tasks they undertake. Especially after the reform of vocational education, colleges and universities not only accept mere academic students, but also the vocational education students who have been on the job. Each of them has its own information use behavior, habits, hobbies and features, as well as user personality. Therefore, there are obvious differences in access to and use of information resources. Only by analyzing and exploring the information needs of different types of users, can the library provide users with different and individualized information services in different phases.

\subsubsection{Timeliness}

The timeliness of users' demand for information resources is as follows:

In the era of network, the speed of information updating is greatly accelerated, and users are increasingly demanding the timeliness of information. Efficient and fast access to information is the common goal of libraries and users for a long time. The advantages of network information resources and the fast and efficient features of network information services further stimulate users' demand for efficient information services.

The stage of users' demand for information resources is as follows:

It is because the update speed of information is too fast, the validity period of information is constantly shortened, and users' demand for information resources appears periodically that they urgently need access to the information of the latest frontiers and the highest academic level with the most valuable research. How to ensure that the information users of universities constantly access to the latest and most cutting-edge scientific and technological information has become an important task of the library.

\subsubsection{Coexistence of Comprehensiveness and Specialization}

The comprehensiveness of users' demand for information resources is as follows:

With the development of network era, the amount of information has increased at an unprecedented rate and 
people's information awareness has been increasing. They are eager to dabble in various kinds of information, such as science, education, culture, politics, economy, entertainment, professional information and nonprofessional information. In short, under the network environment, users hope to obtain comprehensive, complete, diversified and widely sourced knowledge and information needed for business work and study through the library, and require libraries to provide comprehensive knowledge and information services to meet their information needs.

The specialization of users' demand for information resources is as follows:

With the rapid development of science and technology, the infiltration of a large amount of knowledge and information, and the increasing aging of literature, scientific research has been expanding to related fields, and the interdisciplinary nature of disciplines has become stronger and stronger. Information users not only need general narrative intelligence information, but also need a lot of detailed and specific professional knowledge.

\section{SIGNIFICANCE OF BUILDING A LIBRARY TALENTS TEAM ORIENTED BY USER DEMAND}

\subsection{Needs of Library Construction under the Transformation of Higher Education System}

Paying attention to personnel training is not only the development requirement of Library reform, but also the objective requirement of conforming to the features of vocational education and teaching. While the hardware facilities such as the library infrastructure and collection resources have been constantly improved, there is an urgent need for professionals who can always match it. In order to conform to the features of vocational education, in addition to providing basic book-finding services to users, librarians shall have the professional quality of providing professional information and knowledge services with pertinence and practicality. To cultivate and improve the quality of library staff is not only the responsibility of University libraries, but also related to the sustainable development of libraries [4].

\subsection{Achieving a Win-win Situation between Library Development and User Satisfaction}

The information demands of the users are the basis of the existence of the library. All library activities must meet the demands of users. Therefore, it is especially important to build a team of library information service talents oriented by user demand. High-quality librarians can effectively communicate with users, which is conducive to promoting the understanding and relationship with information users, improving service quality and efficiency, and satisfying users better.

The improvement of user satisfaction can promote good cooperation between users and libraries. Users prefer to retrieve the required resources through the library platform. On the other hand, libraries can better understand the dynamic changing needs of users in the network information age from the interaction with customers. In this way, a virtuous circle will be formed between the library and users to achieve a win-win effect.

\section{CONSTRUCTION OF A TALENT TEAM IN UNIVERSITY LIBRARY}

\subsection{Construction Status of the Talent Team in University Library}

The Overall Structure of the Team is Unreasonable and There is a Shortage of Professionals. From the survey, it is found that the quality of Librarians in Colleges and universities is generally not high. Firstly, their educational level is generally low with single knowledge structure. The structure of discipline and distribution structures are not reasonable. Some personnel can only do some simple daily management work such as borrowing, returning, registering and putting on shelves, and they are not competent for complex reference and guidance services. Secondly, there is a shortage of professional talents. Although the educational level of library recruiters is gradually guaranteed, there is a shortage of corresponding professional talents, especially the interdisciplinary talents who know both library science and related professional disciplines.

The Idea of Management Personnel is Backward and Senior Talents Drain. Unlike front-line teaching posts, libraries are the guarantee units of teaching and scientific research in colleges and universities. Their status and functions are not valued by leaders and relevant departments, which seriously affects the introduction of senior talents. In addition, the fact that "the nature of library work is complex mental work" is not recognized by the society. Minimal opportunity for further promotion, coupled with low welfare and long working hours, makes many senior professionals look for other jobs, thus resulting in a large number of brain drain [5].

The Incentive and Evaluation Mechanism is not Perfect, and the Enthusiasm of Staff is not High. At present, for university libraries, the system of rewards and punishments exists in name only, and professional titles are evaluated in order of seniority, which is sometimes unfair. As a result, some people believe that doing and not doing are the same anyway, thus decreasing their enthusiasm for work. 


\subsection{Strategies for the Construction of a Talent Team in University Library}

Focusing on Demands and Improving the Talent Training Mechanism. The advantages of network information resources and the characteristics of fast and efficient network information service as well as the reform of vocational education have brought great challenges to traditional library work. The quality of librarians is directly related to the development of the library, which requires the library to pay attention to the cultivation of talents. Establishing and institutionalizing a talent education and training system.

More efforts should be made to establish a scientific education and training system, so as to encourage librarians to take learning new knowledge and skills as their foundation. Encouraging librarians to actively participate in learning and training is conducive to improving the overall quality of librarians and adapting to the requirements of the new situation.

Putting People First and Establishing Flexible Incentive Mechanism. Psychological research shows that people need to be motivated to generate motivation, so that they have the initiative and high enthusiasm. Incentives can be either physical or immaterial. For example, promoting fair competition and providing opportunities for everyone to develop ability will be conducive to retaining outstanding talents. Furthermore, all kinds of opportunities of visiting and participating in continuing education shall be provided to broaden the vision of librarians, raise awareness, renew concepts, and realize the sustainable development of librarians themselves.

Open and Fair, Perfecting Talent Assessment Mechanism. The establishment of corresponding performance appraisal system is an effective guarantee for librarians and library work. At present, colleges and universities have carried out personnel performance appraisal work. They develop a performance appraisal system with its own characteristics through investigate and survey according to the special circumstances of the library and link the appraisal with librarians' own development and personal interests. With appraisal, there will be rewards and punishments, thus motivating librarians to work better. It is only by adhering to the principle of open, fair and merit-based appraisal that excellent talents can be placed in the positions most suitable for them.

Introduction and Cultivation, Establishing Subject Librarian System. Subject librarians should possess comprehensive qualities. First of all, subject librarians should establish the concept of lifelong learning. The number of network information resources is growing rapidly, and the validity period of information is continuously shortening. Subject librarians must have the concept of continuous learning and continuous improvement to assist users to obtain the latest cuttingedge, highest academic level and most valuable research information. Secondly, subject librarians should have good communication skills. Subject librarians are the bridge and link between knowledge and users. Only by good communication can they accurately understand users' demand. Moreover, subject librarians should have comprehensive qualities, such as foreign language ability, computer network knowledge, map knowledge and professional knowledge of a certain subject, which are indispensable.

Subject librarians should attach equal importance to introduction and training. Firstly, the library management must pay attention to the introduction of subject librarians. Subject librarians should possess professional knowledge and skilled working skills of the library as well as the profound professional knowledge of the corresponding subject. When introducing talents, it is necessary to pay attention to the construction of subject librarians to create conditions for improving the professional information service of library. Secondly, it is necessary to attach importance to the education and training of the original staff and cultivate the subject librarians in a directional way. In addition to participating in continuing education and training, they can also study the key majors of the university.

\section{CONCLUSION}

The development of computer technology and the popularization of the network make the library user groups and user demands appear new features. In order to adapt to the change, the library also pays attention to the demand and constructs a high quality talented person troop by taking the user as the orientation through the establishment subject librarian system to meet the challenge.

\section{REFERENCES}

[1] Zou Wanfen, A Conception of Talent Team Construction Planning for the Library, The Library Journal of Shandong.2020 (1), pp.38-41.

[2] Liu Haiping, Considerations on construction of medical library professionals in big data era, Chinese Journal of Medical Library and Information Science, vol. 28, 2019 (2), pp.65-68.

[3] Zhang Qianyong, Zhang Yichuan, Sun Mingming, Research on the Building of Talents Team of Grassroots Public Libraries in the Background of the Reform of Professional Title System, New Century Library, 2018 (10),pp.70-73.

[4] Quan Qin, Sustainable Development of Public Libraries and Talent Team Construction, Management Observer, 2018(26), pp.95-97.

[5] Zhang Yuan-mei, The influence of librarians' quality on the development of libraries, HEILONGJIANG SCIENCE, vol.10, 2019, pp.2325. DOI: $10.3969 /$ j.issn.16748646.2019.11.009 